\title{
Research on the Green Streets Planning of Sponge City
}

\author{
Wenjun Wang ${ }^{1, a}$ and Hongxing $\mathrm{Yi}^{1, \mathrm{~b}}$ \\ ${ }^{1}$ City College of WUST, Wuhan, China \\ aWangwenjun2016hy@163.com, byihongxing2016hy@163.com
}

Keywords: Sponge City; Green street; Design

\begin{abstract}
Water is the origin of life, and urban development is closely related. But China's current irrational urbanization has fragmented the symbiotic relationship between man and water, and between the city, leading to storm water pollution, urban wrong, falling water tables and other issues. The study based on the city from the perspective of the sponge, and explores the city streets potential ecological management of rain, and the corresponding development strategies, making territorial and humane care and green streets. The first, and summarized the green street design strategy. Firstly, the modular construction methods; secondly put forward a comprehensive transformation strategy three kinds of urban green street. Second, for the green street design strategy involved storm water management facilities, detailing the green street design commonly used in sustainable storm water management facilities and a comprehensive evaluation. Expanding city hard surface, greatly increasing the pressure on urban drainage, but also to erosion and storm water runoff pollution problems become more prominent, so that these problems of urban water environment has become more vulnerable. Storm water management within the city limits is a comprehensive and systematic project; to completely get rid of the dilemma we need efforts from multiple angles.
\end{abstract}

\section{Define the Concept of Sponge City and Green Street}

Definition and Characteristic of Sponge City. Literally understood, sponges city means the city can be like a sponge, a "flexible", "filter" and "water" three properties. Having good "flexibility" to adapt to environmental change and response to natural disasters, etc; the face of urban transport, industrial pollution of storm water runoff, sponge's city also has a "filtering" rain pollutants characteristic; when the storm struck, the exhibits excellent water, water feature.

In the sponge urban background, with concurrency approach in urban construction mainly in the following three aspects: First, to protect the original ecosystem-based. Hydrological original property before land development and utilization of respect included, for rivers, lakes, wetlands and other ecologically sensitive zones to maximize protection. Sort out and understand the internal water system network link, retains a sufficient amount of water has a self-cleaning function and ecological conservation functions. Evaporation intensity of the rainfall intensity and large woodlands, grasslands, wetlands and other areas, should maintain the original natural hydrological characteristics. In the process of industrialization has suffered water damage to the environment and the natural vegetation of the environment, the use of green engineering techniques and tools to repair, stimulate its own resilience to remain at a relatively stable equilibrium. In urban planning level, should be to reduce interference on the ecological environment is an important principle, the reasonable control of the scale of development, retains a sufficient amount of ecological land in space, such as natural rivers and lakes. Carrying out the necessary urban construction process, should reduce the impact on the environment, the use of green engineering and technical means of reducing urban impervious pavement area, proper excavation of water ditches to improve water area, thereby reducing the maximum city development on the nature of the impact and damage.

Definition of Green Street. Green Street belongs to the category of green infrastructure, urban green infrastructure network system an important part. Green Street in space should be mutually connected greenways, wetlands, rain gardens, forests and other green infrastructure, forming material, biological, energy, communication systems. Currently relevant scholars for Green Street concept, there are two narrow and broad points. The streets are narrow green mimic the natural rain 
cycle ways, using different storm water management facilities such as biological landscape ditch, infiltration basin, is the form of street streets streetscape and storm water management of construction combined. Generalized Green Street to expand its range of applications on the basis of narrow, it is to build a unified form of street streets surface rain, rain roadside buildings, street traffic, street view, open and manage a comprehensive system to play in the regulation of city streets green rain the role of flood areas. The Green Street is defined as: Green Street is in line with the concept of ecological urban complexes, water resources recycling as the core of the urban landscape streets. Also includes urban roads storm water control, reduce dust and noise reduction, carbon emissions and other functions, and can provide a unique regional characteristics and humane care of streetscape space for urban residents.

\section{Design Strategy of Green City}

Community Street. After a fine community streets storm water management design, use of natural resources, ecological protection, sustainable economic development. Street furniture designed by green plants through rainwater purification process, bringing together the community center is located in the residence lake, and then slowly release the water from there to make it into a nearby river. All community streetscape and parking are both versatile and integration, and as a service core water green infrastructure. Parking area uses rainwater collected dynamically monitor, with the application of native plants, the blue-green basic fusion community facilities, to create a new type of human living space and landscape areas. Humane theory, will be integrated into the design to the needs of people, a small corner of the square, the space for the neighborhood talking, children playing football provide a venue. While Street View is designed for walking and ready to share the traffic concept also means vehicles can enter the site, and the underground garage, carport, and hidden between the exclusive, able to take the weight matrix planting gardens, neatly arranged parking space for parking the vehicle provides a variety of choices. Convenient for people to travel to play both, the success of abandoned industrial areas into entertainment suitable for people living in residential areas.

Share Streets. Shared core street people and vehicles are to create coexistence street environment, and therefore the need to break the partition between the roadway and the sidewalk, forming a single road, form a unified street pavement. For single road pavement design has the following requirements: first to meet the comfort of pedestrian pavement should have a variety of forms and colorful flat pavement style. Shared space street structure uncertainty and concerns may be formed inside the driver "mentally deceleration zone", which naturally reduce speed and improve safety. The second should have sufficient capacity, to meet the needs of car dealers. Third, we must ecological function as the core, to meet the city streets storm water management requirements, to achieve low interference environment, use permeable surface layer. Some ample space shared garden in the street may be provided, which can be set to a small portion of green storm water treatment facilities, such as holding ponds, rain gardens, etc., used to collect street within the catchment range. On the one hand increases the complexity of the shared neighborhood, traveling speed can be reduced, increasing household traffic safety level; the other hands, to meet the urban residents living recreation function.

Ecological Greenway. The width of the central green belt requirements: the current standard in the United States, the provisions of the median width should be controlled at $3-18 \mathrm{~m}$. The relevant provisions of the Japanese, the median strip width should be $0.5-4.5 \mathrm{~m}$. In view of our urban land resource constraints, the width used by the US standard is clearly not appropriate, in order to ensure traffic safety and ecological functions to play, it is recommended central green band width $1.5-4.5 \mathrm{~m}$. Central green belt height requirements: When designing the height of the center of the green belt, needs to take into account the vehicle's anti-chord line function. Therefore, the height should be the height of motor vehicle headlamps, driver's eye level, road conditions and other uncertainties related models. Too low to achieve the purpose of anti-chord; if too high would undermine the continuity of the highway landscape; it has an adverse effect on the psychological drivers and passengers. Central green belt height should generally be controlled at about $1.5 \mathrm{~m}$, while at the high 
branches of trees should not be higher than the height of the car headlights, such as below this height should be planted low shrubs supplement. Storm water management facilities: central green belt located in the city center of the lane expressway, the position is very suitable for the transformation of Green Street storm water management facilities: through the transformation of curbs, the central green belt can easily collect rainwater from both sides of the driveway. Design, the central green belt can and planting gangue combine to form a place with rich plant communities Jean rainwater transfer channel.

Greenway Eco mode by switching the public transport mode, set up a special bus lanes, bicycle lanes and sidewalks, and to be protected and isolated by soft permeable landscape to enhance public transport and cycling, pedestrian environment, experience and other low-carbon transport mode. Reduce private car usage from the source. Typical elements of ecological boulevard include bike lanes and spacious sidewalks. Pedestrians and cyclists need to be more comfortable space; the first to set up dedicated bike lanes, bike lanes width strict rules, use of road material is suitable to ensure the safety of bicycle travel. To set up the second green belt separating the motor vehicle flow, make full use of plant-based sources of pollution and to reduce the effects of noise, isolate the motor vehicle lanes and bike paths. Improve the quality of walking and cycling experience.

\section{Facilities System of Green City}

Flow Control Facilities. Flow control device - generally include: diversion wells, stone ground shunt with bunk depression, osmotic water weir, curbs, water column now, mounds cropping and hydraulic dichotomy other seven to slow the storm peak emission, dispersion flow. Flow control means disposed mainly concentrated rainfall region after the formation of the high-speed flow easily, such as grass ditch and open channels, etc., it is to make the runoff into the storm water management system before get weakened. Such devices may be dispersed and slow surface runoff and discharge pipes, larger particles of the precipitate and therefore can be separated. The purpose of these devices is to improve the facilities to other green street functions, preventing water erosion and scour. By preclude the use of flow control device, effectively reducing the destructive storm runoff, rainfall peak water flow and sediment content for downstream facilities to reduce the burden. Such facilities require regular management and maintenance, to remove excess sediment, garbage and debris, to ensure the normal functioning.

Detention Facilities. During construction, the planting of new grass beam resistance is weak, susceptible to water invasion candle, need strengthening protection. Depending on the planting of grasses, the use of different colors and textures with plant, grass gangue can improve landscape effects site, provide habitat for wild animals and insects. Maintenance measures include controlling the growth of plants and removal of debris and garbage. Di also requires regular inspection, annual penetration rate and extent of beautiful grass gangue monitoring and evaluation. Underground storage of rainwater reservoir system is a temporary function, before entering transmission pipelines to guide rainwater retention and slow penetration of engineering devices. When the subsoil has good permeability, the storage system can store and slowly release rain sponge to urban facilities network. Underground storage facilities can be used on the ground there is no available storage space. Established on the basis of the site investigation permeability and rainfall on the design of a suitable storage capacity, but also has the potential to penetrate the water storage facilities.

Catchment Facilities. Rainwater is ducted to a permanent reservoir of rainwater underground structures. Rainwater culvert will help slow down storm water runoff, at the same time less processing. As a permanent storm water retention facilities, rainwater discharge rain water can easily ducted, compared to other underground storage device that can remove more precipitate. Therefore, ducted rainwater runoff control has the potential to reduce peak discharge, collection and control sediment. Rainwater ducted mainly serve the limited surface area of the street, site, its rugged construction and easy to clean, and therefore require less maintenance: regular inspection nozzle out while removing large particles of sediment and pollutants can be attached. Holding pond advantage is capable of forming a good aquatic habitat landscape effect. So bottom venting means shall be provided for aquatic plants provide enough oxygen. Create a healthy environment for 
aerobic aquatic organisms and integrated rainwater management is very important, and therefore the need for regular check drains performance, snorkel oxygen function, clarity of water bodies, as well as the growth of plants. Besides garbage, debris and sediment require periodic removal.

\section{Summary}

Water is neither inexhaustible, in today's social development, the use of water for strength but often overlooked these facts, we are more and more use and pollution of the grace given human nature gift, but also essential for the survival of the gift. If we do not hope for the future of anhydrous available, we must have broad thinking; lay down the rule of nature, a natural way to establish water use management system. Sustainable storm water management for the construction of the state and society has considerable economic, social and ecological benefits, but for individuals and developers, it is difficult to obtain direct economic returns. Therefore, in this context, it needs the state has adopted a compensation policy financed the construction of the city to carry out the sponge through economic means to stimulate all social forces; to establish their green street construction of special laws and regulations to provide effective protection for the construction of green streets. Today the United States, Japan and other developed countries in building Green Street has been a long practice, it has produced many sustainable storm water management methods have different emphases. In the next practice, blindly copy the experience of his country is not desirable, according to how the natural, social, economic and cultural characteristics of our city and choose consistent with the construction of green streets way, it is my future work efforts.

\section{References}

[1] Qiu connotation sponge City (LID), Ways and Prospect. Urban Construction .2015 (02)

[2] Zhao Jing, Li Dihua storm water management under way Urbanization - Based on the perspective of low-impact developmen.2011 urban issues (09)

[3] Wang Rusong urban complex ecology and ecological infrastructure. Modern Property (on Xunkan). 2012 (10)

[4] Maureen, NEGATIVE build urban green sponge - Ecological Rainwater Regulating System Planning. Urban Studies .2012 (05).

[5] Zhangshan Feng, Wang Jianyun Green Street - Landscape Methodology road storm water management. Chinese garden .2012 (01)

[6] Dongshu Qiu, Han Zhigang study based on "eco-sponges city" built rainwater utilization planning. Urban Studies .2011 (12) 